\title{
OS MUSEUS DE TERRITÓRIO ENQUANTO ESTRATÉGIA DE MOBILIZAÇÃO DO PATRIMÔNIO AMBIENTAL E CULTURAL
}

GABRIELLE ALVES REIS, UNIVERSIDADE FEDERAL DO RIO DE JANEIRO, RIO DE JANEIRO, RIO DE JANEIRO, BRASIL'

Geógrafa pela Universidade Federal do Rio de Janeiro (UFRJ), mestranda em Geografia (Organização e Gestão do Território) pelo Programa de Pós-Graduação em Geografia da Universidade Federal do Tio de Janeiro (PPGG/UFRJ). Participa do Grupo de Estudos e Pesquisas em Política e Território (GEOPOLL). Orcid: https://orcid.org/0000-0002-3183-0117

http://doi.org/10.11606/issn.1980-4466.v16i31p69-94 


\section{OS MUSEUS DE TERRITÓRIO ENQUANTO ESTRATÉGIA DE MOBILIZAÇÃO DO PATRIMÔNIO AMBIENTAL E CULTURAL \\ GABRIELLE ALVES REIS}

\section{RESUMO}

O uso da memória e do patrimônio são importantes estratégias para a institucionalização de novos discursos e para refletirmos sobre relações em diversas escalas. Um dos principais instrumentos para tal construção são os museus. Os museus, como instituições de memória constroem uma narrativa que privilegia determinada história e, por consequência, ocasionam o esquecimento de outras. Portanto, podemos apontar os museus como instituições com um sistema de relações sociais e um conjunto de ideias e valores. No entanto, atualmente, é possível perceber uma mudança no entendimento do que é museu: o campo da museologia se expande e mesmo os museus tradicionais não ficaram imunes à emergência da pluralidade. A partir da década de 1970, com Varine e Rivière, o modelo de ecomuseu ganha amplitude, em uma integração de projetos museológicos diversificados, associados aos conceitos "museus de comunidade" e "museu de território". Nestes contextos, estão presentes diversos agentes, que consideram características políticas, culturais, econômicas e territoriais que influenciam na maneira como o dispositivo é utilizado, com valor simbólico atribuído ao local. Portanto, o objetivo desta atividade é compreender de maneira relacional como o patrimônio ambiental e cultural se dialogam e se destoam tendo como objeto de análise os museus de território, em contraposição aos museus tradicionais, especialmente. Apesar de diferentes tipologias nessa categoria de museu, que, aparentemente, separam o ambiental do cultural, entre ecomuseus e museus de território/ desenvolvimento comunitário, é possível perceber como os caminhos se dão juntos, com mais semelhanças que diferenças.

\section{PALAVRAS-CHAVE}

Museus, Memória social, Identidade cultural. 


\section{TERRITORY MUSEUMS AS A MOBILIZATION STRATEGY FOR ENVIRONMENTAL AND CULTURAL HERITAGE

\author{
GABRIELLE ALVES REIS
}

\section{ABSTRACT}

The use of memory and heritage are important devices to institutionalize new discourses and to reflect on institutional relationships at different scales. One of the main instruments for this construction are the museums. Museums, as memory institutions, build a narrative that privileges a certain history and, consequently, cause others to be forgotten. Therefore, we can point to museums as institutions with a system of relationships and a set of ideas and values. However, currently, noticing a change in the understanding of the museum is possible: the field of museology has expanded and even traditional museums are affected by the emergence of plurality. Since 7os, with Varine and Rivière, the ecomuseum model gains amplitude, in an integration of diversified museological projects, associated with the concepts "community museum" and "territory museum". In these contexts, several agents are present, which consider the political, cultural, economic, and territorial that influence the way the device is used, with symbolic value attributed to the place. Therefore, this activity aims to understand in a relational way how the environmental and cultural heritage dialogue and diverge, using territory museums as object of analysis in contrast to traditional museums, especially. Despite the different typologies in this category of museum between ecomuseums and territory/community development museums, which apparently separate the environmental from the cultural, seeing how they go together, having more similarities than differences, is possible.

\section{KEYWORDS}

Museums, Social memory, Cultural identity. 


\section{INTRODUÇÃO}

Ao observarmos políticas de memória e patrimônio e os projetos culturais a elas relacionados, percebe-se o crescimento nos debates para novas propostas, impulsionadas principalmente por grupos subalternizados. A questão se torna, assim, cada vez mais política, a partir das tensões entre os diferentes agentes e instituições e isso tem se intensificado também nas práticas museais.

Durante muito tempo, esse caráter político dos museus esteve associado a formações de comunidades imaginadas (ANDERSON, 1987) por meio da construção de narrativas oficiais do Estado-nação. Como Fonseca (1997) coloca, no entanto, é preciso questionar o valor quase intrínseco ao patrimônio, que tende a ser naturalizado a partir de objetos que constituem ou legitimam discursos. A origem do patrimônio remonta ao mundo romano, como um conjunto de heranças transmitidas de pai para filho, revelando o exercício do poder simbólico (LIMA, 2012).

Tradicionalmente, os museus têm suas imagens associadas a templos de musas gregas, como uma biblioteca de estudos e inspiração artística, filosófica e científica (LIMA, 2012). Identifica-se como um local próprio à memória e preservação, contando com as representações de um local.

Nos últimos anos, portanto, essa prática da construção de museus tem sido apropriada por diferentes grupos como estratégia de mudança 
social e esse caráter das instituições museológicas já é mesmo reconhecido pelas organizações internacionais e pelas instituições oficiais de cultura.

Segundo a definição mais recente do Icom, como referência na comunidade internacional, atualizada na $22^{\text {a }}$ Assembleia Geral em Viena (Áustria), em agosto de 2007, o museu se define por:

uma instituição permanente e sem fins lucrativos, aberta ao público a serviço da sociedade e de seu desenvolvimento, em que são adquiridas, conservadas, pesquisadas, comunicadas e exibidas as heranças tangíveis e intangíveis da humanidade e seu ambiente, com propósitos educativos, acadêmicos e de entretenimento.

Portanto, os destaques nessas representações apresentam atributos de valor, como pertencentes ao povo. Dessa forma, o museu configura-se como uma instituição de exercício do poder simbólico (BOURDIEU, 1989), legitimado na preservação do patrimônio. Assim, esse local representa um "lugar de memória" (NORA, 1993), onde a memória coletiva atua no imaginário social, sendo o museu um "permanente (re)fazedor de significações" (LIMA, 2012, p. 39).

Halbwachs (1990) destaca que o tempo da memória só se concretiza quando encontra a resistência de um espaço, além de um grupo para existir. $\mathrm{O}$ autor afirma que a memória coletiva é o conjunto de lembranças construídas socialmente e referenciadas a um conjunto que transcende o indivíduo, retém do passado o que é capaz de viver na consciência de um grupo, sempre se redefinindo. No caso de espaço ou grupo se alterarem, a memória coletiva também é alterada.

Com isso, a Museologia está atenta não apenas aos museus tradicionais, baseados nos objetos, mas também nos chamados museus de território, "relacionados ao patrimônio material e imaterial das sociedades do passado e do presente" (SCHEINER, 2012, p. 18), além de outros tipos, como os museus virtuais, com metodologias e teorias específicas.

Os museus de território surgem, então, como uma resposta aos museus tradicionais, baseando-se na musealização de um território, com ênfase dada às relações culturais e sociais homem/território, ao valorizar processos naturais e culturais, e não os objetos enquanto produtos da cultura, baseada no tempo social. No Brasil, alguns segmentos de grupos subalternizados estão presentes nesse conceito de museu, muitas vezes 
como reação à desterritorialização. Esses locais surgem nas favelas, em bairros periféricos das regiões metropolitanas, no interior, em aldeias indígenas ou em demais áreas com a presença desses grupos. Eles estão ligados a lutas pela cidadania, pelo direito de minorias, pelo reconhecimento de culturas marginais.

Diferentemente de um museu tradicional, esses museus, embora abertos a um público amplo, visam a comunidade na qual eles estão instalados, a fim de que ela se reconheça neles e, portanto, seja valorizada por si mesma, contribuindo para a manutenção de sua identidade. Geralmente, os objetos em um museu de território permanecem em seu contexto original, são inventariados, mas continuam fazendo parte da vida das pessoas, servindo a elas.

Com isso, a tríade tradicional (edifício, coleção e público) é ampliada e passa a ser território de ação, patrimônio coletivo e comunidade de habitantes. Assim, o museu lida com o patrimônio tanto material como imaterial, em uma atuação conjunta com a sociedade, ligada ao desenvolvimento cultural e socioeconômico. O museu é, portanto, de acordo com o Icom (2013), um espaço totalmente imaginário, simbólico, mas não necessariamente imaterial. Moutinho (2014) acrescenta que os museus são entidades prestadoras de serviços, envolvendo diversos conhecimentos, aliando sua relação com os seus públicos.

Entre os museus de território podem ser destacados dois tipos, de acordo com De Carli (2003): o ecomuseu do meio ambiente, voltado para o aperfeiçoamento dos museus ao ar livre escandinavos e das casas de parque americanas, e o museu do Desenvolvimento Comunitário, que busca derivar da comunidade, que possui um papel principal nas ações. Apesar dessa diferenciação apontada por De Carli (2003), o Instituto Brasileiro de Museus (IBRAM) insere os dois na mesma categoria entre os tipos de museus.

Neste artigo, buscaremos entender as semelhanças e diferenças dessas duas tipologias. Quanto à estrutura deste artigo, propomos uma discussão sobre patrimônio, seguida de uma separação entre essas duas tipologias, pensando como podem se conectar a partir de um significado social tanto do ambiente como do território. 
Para tal, utilizaremos um levantamento bibliográfico, elencando a negociação da realidade e do conflito com o patrimônio como espaço de luta material entre grupos com leituras, projetos e apropriações distintas e desiguais, com legados que implicam lutas sociais e políticas, como a demarcação de fronteiras, a semantização de lugares e a definição de espaços de memória, trazendo a discussão da identidade como algo flexível (VELHO, 2006). Em um diálogo associado à memória e remodelamento de alguns desses locais, Diegues (1996) se coloca como um nome fundamental para um vínculo entre as duas partes, em um movimento capaz de pensar nas pessoas que usufruem daquele espaço. Nesse aspecto, o patrimônio é um importante recurso econômico e acrescento aqui também o viés político (MELO FILHO, 2017) como uma porta de entrada para o desenvolvimento de negócios, hoje, extremamente associados ao turismo e ao lazer.

\section{PATRIMÔNIO E MUSEUS}

Como Melo Filho (2017) sugere, o patrimônio surge não só como um meio para desenvolver uma comunidade imaginada, mas como um recurso de governo. Surgindo enquanto ideia de propriedade/posse, a ideia do patrimônio estava em marcar a continuidade histórica, inventando as tradições, pela construção da identidade pelos Estados nacionais. Segundo Choay (2001), para marcar e perpetuar a identidade, é importante marcar o espaço com determinados símbolos que constroem certa identidade, em uma estratégia de fazer lembrar por meio da marca no espaço. $\mathrm{O}$ patrimônio diz respeito a discurso, prática, estratégia e agentes, desde organizações multinacionais governamentais até ONGs ambientalistas. A convergência entre o ambiental e o cultural está, principalmente, na conservação, capaz de nos levar ao avanço da ciência geográfica, historicamente entendida como uma interface entre natureza e cultura, com essas fronteiras cada vez mais borradas.

Em um movimento nacional, a execução e escolha do que é patrimônio atende também ao uso científico e educacional, em especial, a partir do século XIX, a partir das comunidades de interesse, como aponta Anderson (1987). Com a Revolução Francesa, objetivando a fundação do novo e o esquecimento do passado, os bens são ressignificados. As comunidades imaginadas, de Anderson (1987), atentam ao que é construído, atendendo 
a interesses comuns: a identidade é tida a partir da oposição ao outro. Isso pode ser visto em diferentes escalas, como símbolos de determinados grupos. A comunicação é dada marcando o espaço, com monumentos, por exemplo, como feitos para lembrar ou preservar determinados elementos escolhidos. Um monumento é um símbolo capaz de educar e construir um cidadão nacional.

Choay (2001) destaca que monumentos marcantes utilizam critérios nacionais, mentais ou epistêmicos, técnicos, estéticos ou éticos, a fim de marcar e perpetuar a identidade. Ou seja, a construção de símbolos no espaço determina a construção de identidade e memória, indicando como os valores possuem relações com espaço e tempo. É por meio do diálogo dessas duas perspectivas que encontramos a formação do patrimônio, no século XIX. A memória, portanto, não é natural, mas é construída a partir de certos interesses, divergências e conflitos. A construção de narrativas nos indica os lugares de memória, com uso de simbologias para retratar a identidade.

Os museus detêm um importante papel na formação do pensamento social, pois neles encontram-se materializados discursos sobre a história e sobre o território. A exposição é utilizada como narrativa materializada e "comprovada" a partir de objetos, que conferem legitimidade e veracidade aos trechos representados. No século XIX, encontrávamos museus tradicionais, como os de História Natural, Taxidermia, Artes, entre outros. No entanto, os museus na "modernidade" assumem um novo papel, o de legitimadores das identidades nacionais e pedagogos da história. No Brasil, o marco dessa tendência foi a criação do Museu Histórico Nacional (MHN), em 1922.

Contudo, a identidade territorial pode ser trabalhada em diversas escalas, desde o local, passando pelo regional e nacional e, até mesmo, global, como se observa no Patrimônio da Humanidade, pela Unesco. As políticas culturais, atualmente, contemplam essa multiescalaridade. Dessa forma, encontramos os objetos não mais necessariamente para contar a história de um grande feito, mas inseridos dentro de uma situação ou contexto. Assim, os discursos museal e patrimonial experimentam uma ampliação conceitual, acompanhando alterações nas Ciências Sociais, que reivindicaram a polivocalidade e valorização de grupos marginalizados e minorias. Neste momento, antigas práticas coexistem com novas lógicas de 
preservação e exposição. O "reconhecer-se" tornou-se uma reivindicação. Com o aumento dos objetos que podem ser patrimonializados, percebe-se uma extensão tipológica, além da extensão cronológica, com maiores tempos apresentados. No entanto, identifica-se também uma extensão geográfica, com o patrimônio se espalhando por todas as áreas.

Melo Filho (2017) coloca o ano de 1972 como primordial para a discussão sobre o patrimônio, a partir da realização da Convenção para Proteção do Patrimônio Mundial, Cultural e Natural, primeira articulação política global para proteger elementos considerados de valor mundial. Dessa forma, buscava-se inibir o discurso de que as práticas de preservação seriam vilãs para o desenvolvimento. É neste momento que a Unesco assume responsabilidade em relação à temática patrimonial, quando considera outras organizações envolvidas com o tema incapazes de responder à aplicação de um regime internacional. A Conferência de Estocolmo (1972) também merece destaque nesse período. Nela, é possível identificar a atenção dos arquitetos com a preservação das obras de arte monumentais, influenciados pelas Cartas de Atenas e de Veneza e por ativistas ambientais.

Essa ampliação ocorre no mesmo período da mesa-redonda de Santiago do Chile. O movimento da Nova Museologia, impulsionado por debates no Chile, em 1972, organizados pelo Icom $^{2}$, transformou o conceito de museu: a partir desse momento, casas, fazendas, escolas, fábricas, estradas de ferro, minas de carvão, planetários, entre outros, poderiam receber um olhar museológico. A Declaração da Mesa-Redonda de Santiago do Chile apresenta os valores seculares como ultrapassados, gerando uma procura por novos caminhos no processo de musealização. Nessa direção, o Iphan³, associado ao Ministério da Cultura, em 2004, em seu relatório de gestão sobre a Política Nacional dos Museus, definia as instituições museológicas como práticas sociais colocadas a serviço

\footnotetext{
2 O International Council of Museums (Icom), ou Conselho Internacional de Museus, - é uma organização não governamental que existe desde 1946 e atua a nível internacional a fim de elaborar políticas internacionais para os museus. Possui relações com a Unesco e compõe o Conselho Econômico e Social da Organização das Nações Unidas.

3 No âmbito do Ministério da Cultura, os museus oficiais estavam, em sua grande maioria, sob tutela do Iphan até 2009, quando foi criado o Instituto Brasileiro de Museus (Ibram), com essa função. Recentemente, em setembro de 2018, por meio de Medida Provisória, o Ibram foi extinto e no seu lugar foi criada a Agência Nacional de Museus (Abram).
} 
da sociedade e de seu desenvolvimento e comprometidas com a gestão democrática e participativa.

Qualquer tipo de inventário, assim como a proteção e a conservação, é um processo complexo, uma questão de escolha, exigindo, portanto, definição de critérios. Portanto, a escolha do patrimônio não é puramente técnica, mas um jogo político. Esse jogo perpassa pela construção da narrativa, que deve adquirir uma autenticidade. É fundamental a construção de legitimidade para os discursos de um grupo.

A partir disso, é possível realizar uma análise crítica da política de preservação, muitas vezes utilizada enquanto instrumento ideológico de legitimação do poder estatal, tendo em vista que a seleção de bens a serem patrimonializados é feita pela cultura dominante e para a cultura dominante, no caso do Brasil, a luso-brasileira. Contudo, enquanto o debate acerca da democratização da construção do patrimônio entra em pauta, fica de fora a questão da democratização da apropriação simbólica dos bens.

Entre as funções do patrimônio, tais como a construção da identidade nacional e consolidação dos Estados-nações modernos, um dos princípios mais fundamentais é o da cidadania, visando tornar a nação palpável, com provas materiais das versões oficiais da história e geografia nacionais. Isso nos leva a pensar acerca de um interesse cultural, político e uma justificativa ideológica para essa discussão sobre o patrimônio.

Nesse aspecto, é fundamental entender a prática da cidadania, que apresenta conflito, transformação e preservação, na luta por novos direitos e pressão social por justiça, com base em um novo imaginário político. O poder público e o patrimônio são capazes de ressignificar e dar voz a grupos de menor representatividade, por meio da construção de narrativas, a partir da relação entre marca e retórica. A materialidade e o simbolismo são processos de transformação ao longo do tempo, em um dinamismo frágil e susceptível a novas intervenções.

Melo Filho (2017) aponta que ações políticas de gestão da memória são essenciais para o fundamento de uma unidade territorial e simbólica, como uma forma de o Estado garantir sua atuação sobre determinados espaços e temas, contando uma história sobre o território. Dessa forma, o patrimônio é capaz de compor uma identidade e apresentar uma forma de interpretar o território para os demais, forma essa institucionalizada. 
Com isso, podemos ver que o patrimônio é um meio para criar formas de governo e um recurso político para atingir determinados objetivos e, assim, além de retratar uma narrativa comum a todos, pode ser visto como um meio de levantar agendas governamentais sobre o tema.

Embora não haja apenas uma narrativa contada, podemos destacar uma relação entre memória e cidadania a partir de grupos que buscam a visibilidade a fim de fortalecer vínculos identitários. Nesse sentido, compreendemos a construção que Holston (2011) chama de cidadania insurgente. Para o autor, as cidades surgem como palco privilegiado no desenvolvimento da cidadania, já que há diversos cidadãos marginalizados e alguns considerados não cidadãos, que contestam sua exclusão frente à sociedade, associando a luta pelo direito à cidade. Dessa maneira, a memória é capaz de ser um recurso para que grupos invisibilizados disputem esse direito à cidade.

Nessa perspectiva, Velho (2006) destaca o processo de negociação da realidade ao chamar a atenção para os aspectos de divergência e conflito a partir de valores e interesses diferenciados dos atores envolvidos, em seu caso, no que diz respeito ao patrimônio cultural. Para o autor, esse conflito se reflete no embate sobre o que seria a própria identidade da nação brasileira, com agentes e objetivos diferenciados para um mesmo bem comum, a partir da decisão sobre o que poderia ser valorizado e consagrado por meio das políticas de patrimônio: "independentemente de aspectos técnicos e legais, o que estava em jogo era, de fato, a simbologia associada ao Estado em suas relações com a sociedade civil" (VELHO, 2006, p. 240).

Apesar disso, é possível apontar que há uma maior consciência preservacionista em grupos mais instruídos que atingem representação no legislativo e, consequentemente, maior capacidade de pressionar o poder público, que opera mediante um jogo de interesses. Porém, cada vez mais identifica-se uma maior tentativa de participação da população na reivindicação de representatividade.

Assim, o patrimônio é, portanto, de interesse político e justificativa ideológica. O papel da memória, que antes passava pela construção de identidades coletivas como um dos recursos dos Estados modernos na objetivação e legitimação da ideia de nação, agora tem papel questionador, como é o caso dos museus comunitários, que ainda podem ser pensados na forma mais tradicional dos monumentos, com caráter intencional para 
a conscientização de gerações futuras e lembrança de uma ação ou destino e pensado enquanto um documento.

Dessa forma, é possível pensar a proteção do patrimônio a partir do viés da Geografia Política, diferentemente da vertente mais comum, que pensa a partir do turismo. Isso porque o Estado vem tornando o patrimônio como um problema.

O aparato estatal, atrelado a grupos com autoridade e de gestão, atende à conservação e proteção, inclusive, nos museus. Em museus como em São Gabriel da Cachoeira, o Museu de Bagdá, o Museu Nacional, o Museu de Magia Negra e outros, o patrimônio se constrói a partir da retirada de um objeto da sua circulação no ambiente originário com o objetivo de conservá-lo, tal qual aquilo que foi imaginado como representativo. Em museus comunitários, contudo, o movimento é diferente, já que os objetos do inventário continuam fazendo parte do dia a dia da população.

Apesar de o museu ainda ser o local dos objetos, o que o torna único, essa concepção não encerra o entendimento sobre os museus. Os questionamentos sobre a compreensão do museu como uma instituição centralizadora e com ideais hegemônicos colonialistas data dos anos 1960, sobretudo com o maio de 1968, na França, sob formas de antimuseus (BOLAÑOS, 2002), que buscaram ampliar e renovar as práticas museológicas, considerando outras interpretações e atores.

A partir de então, a sugestão no tratamento do patrimônio é que ele seja visto como integral, considerando sua territorialidade. Dessa forma, o conceito de museu é ampliado e repensado, tendo em vista a diversidade de públicos. Assim, "os museus vislumbram que o patrimônio está no território e, também, é um conjunto de elementos materiais e imateriais que dialogam entre si, ou seja, não estando isolados, fazem parte da dinâmica cultural" (CURY, 2017, p. 186-187).

O museu, dessa forma, torna-se um lugar político (CURY, 2017), que possibilita atualmente a prática da autonarrativa, a fim de ganhar visibilidade e estabelecer diálogo com a sociedade, além de afirmar-se, contudo, como diferente, com suas particularidades, com novas práticas, revendo suas relações e metodologias. Isso possibilita a continuidade da memória, a ligação entre passado, presente e futuro e, sobretudo, conhecimento para manutenção da identidade. 


\section{MUSEUS DE DESENVOLVIMENTO COMUNITÁRIO E CULTURA}

O patrimônio é visto como espaço de luta material e simbólica entre grupos com leituras, projetos e apropriações distintas e desiguais: "legados" implicam lutas sociais e políticas, por meio da demarcação de fronteiras, semantização de lugares e definição de espaços de memória. Entendendo a cultura como um fenômeno abrangente que inclui as manifestações materiais e imateriais, por meio de crenças, valores e visões de mundo, é fundamental reconhecer a importância das manifestações culturais de camadas populares, visando a constituição da identidade da sociedade. Nesse sentido, é importante incorporar uma postura flexível frente a tais fenômenos, garantindo a continuidade da expressão cultural, por meio da preocupação com as possíveis contribuições que a própria sociedade que usufrui do bem pode dar a tais políticas. Assim, a memória enquanto fato social é marcada por relações de poder e disputas entre os grupos sociais, por meio da invenção das tradições. A mudança de forma implica na mudança da dinâmica.

Assim, é possível destacar um intenso debate intelectual e político de como lidar com a memória social e com o patrimônio cultural. Halbwachs (1976) já apontava a importância da organização social do espaço e dos lugares de memória para a construção e a dinâmica de identidades individuais e sociais. Gonçalves (2002) aponta o que é patrimônio a partir da perda. Toda patrimonialização é uma escolha do que deve ou não ser retratado na história oficial. Isso é objeto de conflito entre agentes para refletir a identidade dos Estados nacionais. O patrimônio, assim, é uma categoria de pensamento, uma construção discursiva.

Duarte (2005) destaca que no quadro das grandes instituições de memória inventadas na cultura ocidental moderna, coube aos "museus de história natural" a tarefa de combinar o projeto de produção de uma memória neutra da universalização do saber científico com o desígnio de glorificação particularista das identidades nacionais, como é o caso do Museu Nacional. Essas duas dimensões estão presentes no desenho dessas instituições: enquanto nos museus de arte e história, a identidade nacional era prioridade, nos museus de ciência e tecnologia, a universalização tendeu a prevalecer.

Desde a Revolução Francesa, com as comissões dos monumentos, entendeu-se a importância de abrigar e conservar o patrimônio nacionalizado. 
O museu entra, portanto, como uma instância que exerce o poder simbólico (BOURDIEU, 1989), legitimado para preservar e custodiar o patrimônio como bem público.

Para Velho (2006), "a destruição de referências, monumentos, casas, prédios, ruas, cinemas, igrejas, entre outros, tem consequências nos mapas emocionais e cognitivos dos habitantes de diferentes tipos de localidades" (p. 244-245). Com isso, novos museus tanto são usados para contar histórias sobre lutas de grupos marginalizados como para serem eles mesmos um instrumento de reivindicações. Em oposição a isso estão os que Velho chama de "outsiders" ou "invasores", sem laços dos antigos moradores, visando desfrutar da qualidade de vida e de ascensão social propiciadas nesses territórios que ganham nova visibilidade.

Com o crescimento da museologia social e a ampliação do debate entre museus e a sociedade, o patrimônio pode ser apontado como um recurso político, capaz de combater as desigualdades. Assim, a possibilidade de musealização do território pode servir enquanto estratégia de administração da memória e instrumento de desenvolvimento social (OLIVEIRA, 2013).

Firmino e Segala (2010) apontam que a discussão sobre os sentidos e usos sociais dos museus comunitários urbanos em áreas marginalizadas cresce e se complexifica não só na academia, mas também em instituições públicas, associações e grupos representativos de moradores.

Oliveira (2013) ainda aponta a territorialidade como resultado do processo de formação do território, sendo sua expressão simbólico-identitária. A partir disso, esse território pode ser encarado enquanto um museu; não o museu tradicional, como um edifício e uma coleção que abriga, aberta a um público visitante, mas um novo processo museológico, que serve a uma comunidade de pessoas segundo os referenciais patrimoniais que constituem sua identidade. Esse processo é capaz de superar as diferenças sociais, como um instrumento de prática cultural, por meio da manutenção de determinados hábitos e costumes e da preservação de uma história local.

Chagas (2018) destaca que se, por um lado, marcar o território implica a criação de uma memória favorável à resistência, marcada por signos, e à afirmação de saberes locais em um processo de globalização, cada vez mais homogêneo, por outro, entender que um território é mutável traz ao 
debate a reflexão sobre a construção de estratégias que digam respeito à troca e ao fortalecimento dos agentes museais.

Nesse contexto, o patrimônio territorial atua enquanto reivindicação de relações de poder existentes em determinada área. Tal movimento pode ser estabelecido por meio de estruturas museológicas. Em um panorama mais recente, os museus se constituem não só na musealização de um conjunto patrimonial de certo território, ou no trabalho comunitário, mas na possibilidade que está em qualquer museu de se relacionar com o espaço, o tempo e a memória e atuar junto a grupos sociais. Dessa forma, o museu de território busca trazer um olhar mais voltado à própria comunidade na qual está inserido, em narrativas que atendem a grupos insurgentes. Nesse caso, então, o território tem uma finalidade: marcar poder sobre uma área.

Esse tipo de museu é formado por um percurso a partir de pontos de memória que remetem a locais que foram muito importantes na história do grupo, com a ideia justamente de trazer as memórias à tona. É dessa forma que podemos entender melhor a museologia social, que Mário Chagas (s/d apud CARDOSO, 2015) define seu compromisso com "o enfrentamento de desigualdades sociais e pela ampliação das noções de cidadania e direitos humanos. Com a vida em todas as suas instâncias, não apenas a biológica, mas a de relações".

Ultrapassando o museu tradicional, como instrumento ou função concebida pelo ser humano em uma perspectiva arquivística, de compreensão e transmissão, o museu de território é definido como um

espaço físico estreitamente ligado às tradições culturais definidoras dos agentes locais, ou habitantes ou os ativos do lugar, e apoiando na noção de um patrimônio comum, a imagem de pertencimento, o que se associa e permite-se indicar como questão de identidade cultural (LIMA, 2012, p. 42).

Dessa forma, demandas socioculturais estão em debate, alinhando política e cidadania, reafirmando o papel social dos museus, onde novos grupos estão inseridos na função de decisão como protagonistas dos espaços musealizados, com novos formatos.

Contudo, os agentes que mobilizam tais práticas estão, sobretudo, nos segmentos que exigem maior nível de escolaridade da sociedade. Assim, é possível observar que a memória é seletiva e, por isso, o fenômeno da 
memória pode ser entendido como uma ação política, a partir da discussão e da construção da memória e da identidade. Com isso, é importante questionar, então, quais os objetos que ligam as pessoas a esse território, pelo que ele é conhecido, o que o torna visível, o que o faz ser reconhecido enquanto um território. Dessa forma, a cidade e seu patrimônio trazem questões de interesses, nas quais o conflito é predisposição para a vida social.

No entanto, esse debate não é de hoje, mas surge nos anos 1970, com o modelo ecomuseu de Varine e Rivière, que integram projetos museológicos diversificados, associados aos conceitos "museus de comunidade" e "museu de território".

\title{
4 ECOMUSEUS E NATUREZA
}

Um museu de desenvolvimento comunitário não é a única forma que Varine (2012) entende que o patrimônio, enquanto recurso, deve servir à sociedade em seu todo. Para Rivière (1980), um ecomuseu é um instrumento que um poder e uma população concebem, fabricam e exploram juntos, onde a população é capaz de se reconhecer a partir das escolhas feitas. O ecomuseu, além de ser um fabricante de sentidos, desempenha também um papel informacional e de análise crítica, uma interpretação do espaço. É uma expressão entre o homem e a natureza, na qual o homem é interpretado em seu meio natural. Nesse sentido, o entendimento de natureza do autor é que

\begin{abstract}
A natureza o é na sua selvageria, mas também como uma sociedade tradicional e a sociedade industrial que são aplicadas à sua imagem. Uma expressão do tempo, quando a explicação remonta o início dos tempos quando o homem apareceu, seu estágio através dos tempos pré-históricos e históricos que ele viveu, relacionado com o tempo que ele vive (RIVIĖRE, 1980, p. 443, tradução livre).
\end{abstract}

Nesse sentido, o modelo ecomuseu, criado, a priori, em 1971, por Hugues de Varine, posteriormente desenvolvido em colaboração com Georges Henri Rivière, inicia um movimento internacional, também associado aos conceitos "museu de comunidade" e "museu de território". A definição original do conceito diz respeito a um

museu aberto, interdisciplinar, apresentando o homem no tempo e no espaço, no seu ambiente natural e cultural, convidando a totalidade de uma população a participar do seu próprio desenvolvimento por 
diversos meios de expressão, baseados essencialmente na realidade dos sítios, edifícios, objetos, coisas reais que falam mais que as palavras ou as imagens que invadem a nossa vida (ECOMUSÉE CREUSOT MONTCEAU, s.d. apud LIMA, 2012, p. 42).

O modelo destaca a participação de agentes sociais, personificando, assim, a autogestão, onde a administração e as decisões emanam da comunidade, apesar da possibilidade da presença de museólogos e outros estudiosos da academia. Isso possibilita que a representação de suas identidades seja maior, com foco nas pessoas e não apenas nos objetos. O público é participante ativo, que atua na preservação que atende a ele próprio e à sua memória.

De acordo com o Icom (2013, p. 66), em sua concepção inicial, o ecomuseu se define como

uma instituição museal que associa ao desenvolvimento de uma comunidade a conservação, a apresentação e a explicação de um patrimônio natural e cultural pertencente a esta mesma comunidade, representativo de um modo de vida e de trabalho, sobre um dado território, bem como a pesquisa que lhe é associada.

Para Rivière (1980), o ecomuseu retrata as relações entre o ser humano e a natureza, sobre um determinado território. Entre possíveis aspectos que representam o patrimônio da comunidade à qual ele serve, estão os bens imóveis não construídos, espaços naturais selvagens, espaços naturais humanizados, bens imóveis construídos, bens móveis e bens integrados.

Em 1958, Rivière já apontava a importância do museu na educação. No mesmo documento, em conclusão a um seminário regional de estudos da Unesco sobre o papel educativo dos museus, no Rio de Janeiro, o autor destaca uma apresentação "ecológica" ou integral, como Scheiner (2012) aponta, das exposições, para melhorar a comunicação entre os públicos.

Alguns autores apontam a Declaração de Santiago como uma grande influência no crescimento dos ecomuseus. No entanto, esse debate é anterior a isso, com os museus a céu aberto, museus-ateliês e parques naturais musealizados.

O primeiro museu desenvolvido por Rivière, fundamentado em tais práticas, é o Museu de Artes e Tradições Populares, em Paris (1937), dedicado às relações homem-natureza, com base nas teorias de Lévi-Strauss. Esse museu já antecipa os princípios do ecomuseu, esboçados em 1957, com o 
Museu de Bretanha, e plenamente desenvolvidos em 1969, com o Ecomuseu da Grande Lande, no Parque Natural Regional des Landes de Gascogne (SCHEINER, 2012).

Além disso, Scheiner (2012) destaca que outra característica dos ecomuseus é o fechamento das comunidades em torno de si mesmas, em um movimento de proteção contra a perda de referências, a fim de fortalecer sua identidade.

Assim, é importante pensar que sujeitos ativos levam à transformação da natureza, com responsabilidades tanto individuais como coletivas, como discute Harvey (2004). A construção de regimes discursivos (de responsabilidade), sistemas de conhecimento e formas de pensamento está expressa nas diferenças das concepções eurocêntrica e antropocêntrica, com um debate aflorado entre fins e meios na política ambiental. O ecossistema e a comunidade dependem da escala e do ponto de vista. Com a crise ambiental, identifica-se uma retórica emergencial do colapso associado à retórica da perda (GONÇALVES, 2002). O valor intrínseco da natureza se desloca para a diversidade biológica, com a substituição da conversação da natureza pela conservação da biodiversidade, como uma metonímia, a partir dos anos 1980. Entre as vantagens dessa mudança, identifica-se o próprio discurso iminente da perda, que Gonçalves (2002) aponta, e um senso de urgência para concentrar esforços nas áreas protegidas, com a finalidade de torná-las mensuráveis. Contudo, entre os efeitos, pode-se apontar a inconsistência ética e corroboração científica com o coletivo sobre os indivíduos. Nesse sentido, é fundamental não reduzir a natureza à biodiversidade, mas considerarmos que as pessoas mantêm relações entre si.

Os museus, portanto, possuem como característica essencial a relação com a expressão humana, a sua presença a serviço da sociedade. $\mathrm{O}$ sentimento de pertencimento é o que fortalece essas relações comunitárias. Apesar disso, embora o fundamental seja a comunidade em torno de si mesma, com seus valores e dinâmicas, ainda é importante a aprovação de agentes externos, até por reiterar a sua identidade na diferença

Dessa forma, a participação dos agentes sociais no ambiente museológico, onde criação, administração e decisão emanam da comunidade, é fundamental, embora possa haver outros agentes. 
O discurso sobre a natureza e sua conservação também passa por uma guerra de narrativas sobre o que vai prevalecer, desde Yellowstone. Nesse sentido, é fundamental abordar o contexto social e político no qual o patrimônio está inserido, já que a estrutura centro-periferia dialoga também nesse contexto. A natureza nunca é não social. O discurso ocidental sai como vitorioso e legitima a ação enquanto produção social. No entanto, a natureza é particular, no sentido de não ter um único discurso.

Diegues (1996) aponta que, no século XX, proteger a natureza significava afastá-la do ser humano, com a formação de "ilhas", para admirá-la e reverenciá-la, como é o caso dos parques. Contudo, a natureza em estado puro não existe: é necessário integrar a população local.

Para um melhor diálogo na relação homem-natureza, Diegues (1996, p. 159) aponta que

\begin{abstract}
A nosso ver deve-se rejeitar tanto a visão utilitarista da conservação, pela qual qualquer impacto de atividades humanas pode ser revertido pela tecnologia moderna, quanto a visão estritamente preservacionista baseada no pressuposto de que, colocando-se de lado áreas naturais para conservação, automaticamente se garantirá a integridade biológica. Em países subdesenvolvidos, a conservação poderá ser mais bem alcançada com a real integração e participação das populações tradicionais que, como afirmado anteriormente, em grande parte foram responsáveis pela diversidade biológica que hoje se pretende resguardar.
\end{abstract}

É atendendo a essa perspectiva que os ecomuseus são estruturados, voltados para os ambientes nos quais eles estão inseridos, juntos à população. Apesar desse panorama mais voltado a um viés ambiental, é impossível pensar os ecomuseus sem um ponto de vista do patrimônio cultural. Os ecomuseus trabalham em torno da identidade. Esse tipo de museu também se estende ao envolvimento e desenvolvimento do território, dedicado a seu meio.

Os ecomuseus possibilitaram, então, uma renovação na prática museológica, em sua forma de atuar, relativizando o poder do especialista pelo compartilhamento de decisões com lideranças comunitárias. É um modo de reconhecer a importância da herança intangível.

Com isso, fica claro que o ecomuseu, diferentemente da sugestão do nome a muitos, não está atrelado apenas ao ambiente natural. Na verdade, o eco sugere o integral, bem como a Ecologia, que estuda as relações 
estabelecidas entre os seres vivos e suas interações com o ambiente em que vivem. Assim, o ecomuseu busca integrar o público a suas perspectivas.

\section{IDENTIDADE}

Tendo em vista que o patrimônio cultural e natural das comunidades leva a uma identidade, novos modelos de museus apresentam uma forma que se refere a um contexto. O museu, nesse caso, é um texto. Para obter visibilidade nos espaços políticos e conseguir capital, determinados grupos são capazes de criar estratégias de resistência a partir da ocupação de espaços políticos e transformação de identidades.

O artifício da memória é utilizado como uma importante estratégia nos museus de território. Estamos tratando de experiências subjetivas, que não necessariamente precisam de conexões. Para Pollak (1992), a memória é um fenômeno construído social e individualmente, inserido dentro de um determinado contexto, que apresenta uma estreita relação com o sentimento de identidade.

O sentimento de identidade está relacionado à memória, no entendimento de Pollak (1992), que considera a identidade como "a imagem que uma pessoa adquire ao longo da vida referente a ela própria, a imagem que ela constrói e apresenta aos outros e a si própria, para acreditar na sua própria representação, mas também para ser percebida da maneira como quer ser percebida pelos outros" (VIEIRA, 2013, p. 49). A memória é um elemento

fundamental na construção da identidade, na constituição de lembranças para a formação de sentimentos de pertencimento. Memória e identidade são mutáveis no tempo, constituídas a partir da negociação com o outro, por meio de disputas sociais e políticas.

Nesse ponto, é fundamental entender a prática da cidadania, que apresenta conflito, transformação e preservação na luta por novos direitos e pressão social por justiça, com base em um novo imaginário político e, a partir disso, mostra-se importante entender os agentes que mobilizam a paisagem, que pode ser tomada como o reconhecimento de cidadanias (BARBOSA, 2017).

Os museus, como agentes ativos da territorialização e pertencimento de um grupo social em diferentes escalas, são capazes de produzir discursos que auxiliem na construção de identidade. Anderson (1987) fortalece essa perspectiva ao argumentar que os nacionalismos são produtos de uma 
construção ao longo do tempo, em que a museificação e naturalização de alguns elementos são importantes para a construção das nações. Fica claro que isso se expande também às novas faces dos museus.

Segundo Woodward (2009), a identidade é marcada e definida pela negação do diferente, em uma relação fundamental, constituída por símbolos e linguagens que são parte de um sistema simbólico e social. No caso dos museus, entendemos, na verdade, como a valorização do diferente, daquilo que é natural do lugar. Claval (1999) entende que a identidade deve ser tratada como um discurso dos grupos sobre eles mesmos e sobre os outros, muito pautado na materialidade e na coletividade. Le Bossé (2004) complementa ao definir as identidades como uma definição histórica e social daquilo que é próprio e o que é do outro. O geógrafo Rogério Haesbaert acrescentou a identidade às categorias de território e territorialidade, que na geografia abordam tanto o substrato simbólico quanto o físico. Haesbaert (1999) entende as identidades territoriais como dimensões simbólicas presentes no território, que exercem certo controle e sentimento de pertencimento em relação ao espaço vivido.

Dessa forma, a identidade é apresentada em uma relação entre espaço e tempo. Para Haesbaert (2011), "a própria construção das identidades espaciais - ou territoriais - irá adquirir feições diversas de acordo com a concepção de espaço à qual estiver vinculada" (p. 47). A identidade atende à performance e à eficácia, o que se faz com ela em vez do que ela realmente é. A representação é, portanto, fundamental nesse aspecto.

O direito à memória compõe uma construção da identidade social. Segundo Coracini (2007), a memória é feita de esquecimentos, de silêncios, de sentidos, de sentidos não ditos, de sentidos a não dizer, transformando o que parece igual e intocável. Não há memória neutra. Ela sempre será interpretação, invenção, ficção. Será, portanto, sempre incompleta e, de certa maneira, sempre verdadeira, ao mesmo tempo que é falsa e mentirosa. Essa interpretação está ligada ao que se entende do momento em que se está vivendo.

Dessa forma, o que é essencial aos museus é o serviço à comunidade, o sentimento de pertença. A mudança na sociedade implica diretamente a mudança nos museus, a partir da formação da consciência das comunidades e engajamento delas na ação. Assim, a partir dos anos 1960, com a chamada "revolução comunicacional", que promoveu mudanças na relação com a 
sociedade no que diz respeito à participação, visto que o público tornou-se elemento constitutivo, o patrimônio passou a ocupar o território, com elementos materiais e imateriais que dialogam entre si. Com isso, autonomia e autogestão são fundamentais para a autonarrativa. O método colaborativo aberto é uma ação política.

Sendo assim, é possível apontar que, por vezes, há o fechamento das comunidades em torno de sua própria existência nas narrativas desses museus, em uma proteção contra o sentimento de perda. No entanto, esse exercício de comunicação extrapola o museu. Uma boa comunicação gera reflexões, provoca inquietações e amplia agendas, levando o debate a outros locais. Assim, a visibilidade e a participação proporcionam um alcance político.

O que está em disputa ao tratarmos das identidades nos museus é o poder de impor uma visão de mundo, o consenso presente, que entendemos como a realidade. Dessa forma, os patrimônios são usados como armas nas disputas identitárias, pois permitem aos grupos encenar suas identidades (SOARES, 2017). Os grupos associam-se a essas imagens para que possam existir enquanto grupos. Isso destaca uma afirmação do sujeito enquanto ser político.

\section{CONSIDERAÇÕES FINAIS}

Entre os diferentes tipos de modelos, podemos destacar o tradicional e o museu de território como exemplos. Neles, os elementos são apresentados de forma material, como bens musealizados. Contudo, o contexto que envolve os bens também é representado, pelo imaterial, e compõe a narrativa que esse museu conta. $\mathrm{O}$ texto, portanto, também é contado pelo intangível.

Dessa forma, o museu é um meio de comunicação e não mais o foco principal: nossa relação com a memória e a herança agora é o fundamental. O reconhecimento e a identidade são de suma importância nesse desenvolvimento. $\mathrm{O}$ indivíduo que se encontra em um coletivo se relaciona com a sociedade de maneira diferenciada.

Uma estratégia para se apresentar como diferente é por meio da identidade. Tudo isso prescinde materialidade, que pode ser construída e ligada à forma simbólica. Nesse contexto, identifica-se u ma vontade de memória com uma narrativa construída a partir da materialização de certas escolhas, que também une os ecomuseus aos museus de desenvolvimento comunitário. 
O museu como fenômeno diz respeito à relação entre ser humano, espaço, tempo e memória, com adaptações e leituras do real, baseado nas percepções e valores das culturas, passível de mudanças à medida que a própria sociedade se modifica. Os museus, então, se adequam a essas mudanças para manutenção de um papel social, a serviço da sociedade, na formação de sua consciência e no engajamento de ações (MOUTINHO, 2014).

Simultaneamente à renovação de museus já tradicionais e à criação de novos, surgem os ecomuseus e museus de desenvolvimento comunitário, que visam, por meio de curadoria coletiva e promoção de práticas participativas e populares, a valorização, preservação e difusão dos patrimônios locais, sejam eles de condição natural ou cultural, material ou imaterial, a fim de garantir que o museu seja um espaço de representação e transformação.

Os museus de desenvolvimento comunitário e ecomuseus, no entanto, não se limitam ao que é comum das fronteiras da memória, tanto em suas concepções de memória como nas abordagens do território, como já apontado por Mário Chagas (s/d apud CARDOSO, 2015). O autor aponta que as novas práticas ecomuseológicas variam entre a territorialização e a desterritorialização: ao mesmo tempo que marcar um território pode significar a criação de ícones de memória favoráveis à resistência e à afirmação local frente a processos homogeneizadores, assumir a mutabilidade desse território pode influenciar em estratégias que facilitem a troca e o consequente crescimento de agentes museais. Apesar de ser um ideal dificilmente acessível, o inventário compartilhado e o participativo reforçam a responsabilidade da comunidade sobre o patrimônio e o desenvolvimento local.

Apesar de estarem inseridos na mesma categoria, os museus de território e os ecomuseus possuem uma diferença principal fundamental: enquanto os museus de território são voltados para o desenvolvimento comunitário, os ecomuseus visam mais ao meio ambiente, como uma relação dialógica entre público representado e território. O que os une é a forma como essa ação é realizada, por meio de curadoria coletiva e promoção de práticas participativas e populares, a valorização, preservação e difusão dos patrimônios locais, sejam eles de condição natural ou cultural, material ou imaterial, a fim de garantir que o museu seja um espaço de representação e transformação. 
Fica claro, portanto, que os museus de desenvolvimento comunitário e os ecomuseus têm características que mais os unem do que os separam, o que justifica a classificação presente no Ibram, tanto por questões ideológicas quanto estruturais, com um processo mais democrático. Todos os museus devem servir à sociedade, como um meio de educação e transmissão de informação e conhecimento.

\section{REFERÊNCIAS}

ANDERSON, Benedict. Comunidades imaginadas: reflexões sobre a origem e a difusão do nacionalismo. São Paulo: Companhia das Letras, 1987.

BARBOSA, David Tavares. Cidadania paisagística. In: V SEMINÁRIO ESPAÇO, CULTURA E POLÍTICA. Recife, 2017, 16p.

BOLAÑOS, Maria. La memória del mundo. In: Cien años de museología [190o- 20oo]. Gijón: TREA, 2002. p. 268-297.

BOSSÉ, Mathias Le. As questões de identidade em geografia cultural - algumas concepções contemporâneas. In: CORRÊA, Roberto Lobato, ROSENDAHL, Zeny. (Org.). Paisagens, textos e identidade. Rio de Janeiro: EDUERJ, 2004. p. 157-179.

BOURDIEU, P. O poder simbólico. Rio de Janeiro: Bertrand Brasil; São Paulo: Difel, 1989.

CARDOSO, Diogo da Silva. Arquipélago sociomuseológico regional: notas sobre a emergência de um circuito de cultura e memória na periferia carioca (RJ). Tese (doutorado) - Universidade Federal do Rio de Janeiro, Instituto de Geociências, Departamento de Geografia, Programa de Pós-Graduação em Geografia, 2015, 300 f.

CHAGAS, Mario de S.; PIRES, Vladimir Sibylla. Sociedade, Museus e território. In: CHAGAS, Mario de S.; PIRES, Vladimir Sibylla. Território, museus e sociedade: práticas, poéticas e políticas na contemporaneidade. Rio de Janeiro: UNIRIO; Brasília Instituto brasileiro de Museus, 2018.

CHOAY, Françoise. A alegoria do patrimônio. São Paulo: Estação Liberdade/ Editora UNESP, 2001.

CLAVAL, Paul. Geografia cultural. Florianópolis: UdUFSC, 1999.

CORACINI, M. J. A celebração do outro arquivo, memória e identidade: línguas (materna e estrangeira), plurilinguismo e tradução. Campinas: Mercado de Letras, 2007.

CURY, Marilia Xavier. Lições indígenas para a descolonização dos museus: processos comunicacionais em discussão. Cadernos CIMEAC, v. 7, n. 1, p. 184-211, jul. 2017.

DE CARLI, Georgina. Vigencia de la Nueva Museología en América Latina: conceptos y modelos. Revista ABRA, Costa Rica, jul./dez. 2003.

DESVALLÉES, André; MAIRESSE, François. Conceitos-chave de museologia. Tradução: Bruno Brulon Soares, Marília Xavier Cury. ICOM: São Paulo, 2013. 
DIEGUES, Antônio Carlos. O mito moderno da natureza intocada. São Paulo: HUCITEC, 2008 [1996].

DUARTE, Luiz Fernando Dias. Uma natureza nacional: entre a universalização científica e a particularização simbólica das nações. Tradução parcial de "La nature nationale: entre l'universalité de la science et la particularité symbolique des nations. Civilisations, v. LII, n. 2, Bruxelas, 2005.

FIRMINO, A. C.; SEGALA, L. Memoria social, museu e trabalho comunitário na Rocinha, Rio de Janeiro. Relatório final do projeto Memória Social e trabalho comunitário na Rocinha 19761984. ProextMecCultura. LABOEP - UFF, 2010.

FONSECA, Cecilia Londres. O patrimônio em processo. Rio de Janeiro: UFRJ/Iphan, 1997.

GONÇALVES, José Reginaldo Santos. A retórica da perda: os discursos do patrimônio cultural no Brasil. 2. ed. Rio de Janeiro: EdUFRJ, Iphan, 2002.

HAESBAERT, R. O mito da desterritorialização: do "fim dos territórios" à multiterritorialidade. 6. ed. Rio de Janeiro: Bertrand Brasil, 2011.

HAESBAERT, Rogério. Identidades territoriais. In: ROSENDHAL, Zeny, CORREAA, Roberto Lobato. (org.). Manifestações da cultura no espaço. Rio de Janeiro: EDUERJ, p. 169-190, 1999.

HALBWACHS, Maurice. A memória coletiva. São Paulo: Vértice/Revista dos Tribunais, 1990.

HALBWACHS, Maurice. Les cadres sociaux de la mémoire. Paris: Mouton, 1976.

HOLSTON, James. Cidadania insurgente: disjunções da democracia e da modernidade no Brasil. São Paulo: Companhia das Letras, 2011.

LIMA, Diana Farjalla Correia. Museologia-Museu e patrimônio, patrimonialização e musealização: ambiência de comunhão. Boletim do Museu Paraense Emílio Goeldi. Ciências Humana, v. 1.7, n.1, p.31-50, 2012.

MELO FILHO, Dirceu Cadena. Patrimônio como recurso político: disputas por reconhecimento, fortalecimento e geopolítica entre UNESCO e Cabo Verde. 2017. Tese (Doutorado em Geografia) - Universidade Federal do Rio de Janeiro. Rio de Janeiro, 2017.

MOUTINHO, Mário C. Definição evolutiva da sociomuseologia: proposta de reflexão. Cadernos do CEOM, v. 21, n. 41, p. 423-427, 2014.

NORA, P. Entre memória e história: a problemática dos lugares. Projeto História, v. 10, dez 1993.

OLIVEIRA, Carlos Augusto de. A musealização do território como estratégia de gestão do patrimônio e administração da memória. Revista Memorare, Tubarão, v. 2, n.2, p. 34-51, jan./ abr. 2013.

POLLAK, Michael. Memória e identidade social. Revista Estudos Históricos, Rio de Janeiro, v. 5, n. 10, p. 200-215, jul. 1992. ISSN 2178-1494. Disponível em: <http://bibliotecadigital.fgv.br/ojs/ index.php/reh/article/view/1941/1080 >. Acesso em: 24 jan. 2020.

RIVIÈRE, Georges Henri. L'Écomusée, un modèle évolutif. In: WASSERMAN, F. (Ed.) Vagues: une anthologie de la nouvelle muséologie. v. 1 M.N.E.S., 1992 [1980], p. 440-445. 
SCHEINER, Tereza Cristina. Repensando o Museu Integral: do conceito às práticas. Boletim do Museu Paraense Emílio Goeldi. Ciências Humanas, v. 7, n. 1, p. 15-30, jan.-abr. 2012.

SOARES, Bruno Brulon. Paisagens culturais e os patrimônios vividos: vislumbrando a descolonização, para uma musealização consciente. Museologia e Patrimônio, v. 10, n. 1, p. 65-68, 2017.

VARINE, Hugues de. As raízes do futuro: o patrimônio a serviço do desenvolvimento local. Porto Alegre: Medianiz, 2012, 256 p.

VELHO, Gilberto. Patrimônio, negociação e conflito. Mana, v. 12, n. 1, p. 239-248, 2006.

WOODWARD, K. Identidade e diferença: uma introdução teórica e conceitual. In: SILVA, T. T. (org.); HALL, S.; WOODWARD, K. Identidade e diferença: a perspectiva dos estudos culturais. 9.ed. Petrópolis: Vozes, 2009. p. 7-72.

(c) 